\title{
Anti-Trypanosomal Potential of The Red Sea Soft Coral Nephthea Mollis Supported by Metabolomic Profiling and Molecular Docking Studies
}

Khaled M. Allam ( $\sim$ dr_khaled1986@yahoo.com)

South Valley University Faculty Of Pharmacy https://orcid.org/0000-0002-3442-1124

Yaser A. Mostafa

ASUITs: Azienda Sanitaria Universitaria Integrata di Trieste

Usama R. Abdelmohsen

Minia University

Amgad I.M. Khedr

Port Said University

Ahmed E. Allam

Al-Azhar University

Mostafa A. Fouad

Minia University

Ehab S. Elkhayat

Al-Azhar University

\section{Research Article}

Keywords: Anti-trypanosomal, metabolomic profiling, Nephthea mollis, Trypansoma brucei, docking

Posted Date: November 24th, 2021

DOI: https://doi.org/10.21203/rs.3.rs-1090567/v1

License: (9) (i) This work is licensed under a Creative Commons Attribution 4.0 International License.

Read Full License 


\section{Abstract}

The total ethanol extract and its derived ethyl acetate fraction of the soft coral Nephthea mollis displayed remarkable in-vitro anti-trypanosomal potential against Trypanosoma brucei with $\mathrm{IC}_{50}$ value of 6.4 and $3.7(\mu \mathrm{g} / \mathrm{ml}, 72 \mathrm{~h}$ respectively. Consequently, the total ethanol extract was subjected to LC-HR-ESI-MS metabolomic profiling to discover the constituents that possibly underlie their bioactivities. Therefore, thirty-three secondary metabolites were characterized, among them, sesquiterpenes and diterpenes were found to prevail. In silico modeling was carried out on the dereplicated compounds to provide an insight into their anti-trypanosomal mechanism of action with docking study on ornithine decarboxylase (ORD) which illustrated that five of the dereplicated compounds (2-deoxy-12-ethoxy-7-O-methyl lemnacarnol, Nephthenol, 4a-O-acetyl-selin-11-en, Eudesma-4,7(11)-diene-8 $\beta$-ol, and Chabrolidione A) have the highest affinity to the ornithine decarboxylase enzyme. These results highlight the valuable chemical profile of Nephthea mollis as a lead source for anti-trypanosomal natural products.

\section{Introduction}

Trypanosomiasis or sleeping sickness is a parasitic infection caused by Trypanosoma brucei which is transmitted generally by an infected fly called tsetse, leading to a huge health topic, particularly in the tropical region. The global prevalence of African trypanosomiasis is approximately 600.000 every year [1]. Due to the relatively limited market and the high cost of developing new drugs, there are a few antitrypanosomal drugs available, so there is a great demand for discovering natural products that are effective, safe, and affordable as anti-trypanosomal [2].

Metabolomics is a valuable analytical tool used in the comprehensive, highly accurate determination of metabolites in a given metabolome [3-5]. This valuable technique allows the rapid identification (dereplication) and quantification of secondary metabolites in crude unfractionated extracts [6-10].

The literature survey demonstrated that the genus Nephthea is rich with secondary metabolites including sterols, sesquiterpenes, and diterpenes. Many of these metabolites recently showed a range of biological potentials such as antiviral, cytotoxic, antifouling, antimicrobial, and anti-inflammatory activity [11-14].

The current approach aims to evaluate the in-vitro anti-trypanosomal potential of the total ethanol extract (TEE) and its derived fractions; petroleum ether and ethyl acetate of Nephthea mollis assisted by LC-HRESI-MS metabolomic profiling to identify the secondary metabolites contributed to this anti-trypanosomal potential of the soft coral. Moreover, in-silico molecular docking simulations within ornithine decarboxylase (ORD; which is the enzyme catalyzing biosynthesis of polyamines in Trypanosoma brucei. ORD is a drug target for the treatment of African sleeping sickness disease and its X-ray was deposited at RCS protein data band as 1 NJJ PDB protein) for dereplicated compounds were performed to help better understand the binding mode and their possible anti-trypanosomal mechanism of action $[15,16]$.

\section{Results And Discussion}




\subsection{Anti-trypanosomal activity}

Using the protocol of Huber and Koella, the total ethanol extract and its derived fractions; petroleum ether, and ethyl acetate of Nephthea mollis were tested for their in-vitro anti-trypanosomal results against $T$. brucei revealed that the total ethanol extract and ethyl acetate fraction of the soft coral Nephthea mollis displayed remarkable in-vitro anti-trypanosomal potential against Trypanosoma brucei with $\mathrm{IC}_{50}$ value of 6.4 and $3.7(\mu \mathrm{g} / \mathrm{ml}, 72 \mathrm{~h})$ respectively. Unfortunately, the Petroleum ether fraction shows a weak antitrypanosomal activity with $\mathrm{IC}_{50}$ value of $>50(\mu \mathrm{g} / \mathrm{ml}, 72 \mathrm{~h})$.

\subsection{Metabolomic analysis}

The total ethanol extract of Nephthea mollis was subjected to metabolomic profiling, for the first time and the chemical profiling revealed various classes of secondary metabolites, where sesquiterpenes were the most abundant, in addition to diterpenes and terpenoid-related carboxylic acids (Figs.1 and 2). The detected compounds were identified by using macros, algorithms using MZmine, and online databases (DNP, METLIN, and Marinlit databases) [17]. From these databases, thirty-three compounds were identified (Table 1; Fig.3). Fig.1. Total ion chromatogram of total extract of Nephthea mollis (Negative mood).

The mass ion peak at $m / z 204.187$ for the suggested formula $\mathrm{C}_{15} \mathrm{H}_{24}$ was identified as Cadina-4(14),5diene (1) which was formerly reported from the soft coral Nephthea sp. [18]. Likewise, the mass ion peak at $m / z 204.187$ for the predicted molecular formula $\mathrm{C}_{15} \mathrm{H}_{24}$ was also dereplicated as the sesquiterpene; 4,15-dihydro guaian-6,10-diene (2), which was previously obtained from Nephthea chabrolii [19]. Additionally, the mass ion peak at $m / z 220.183$ in accordance with the molecular formula $\mathrm{C}_{15} \mathrm{H}_{24} \mathrm{O}$, was dereplicated as eudesma-4,7(11)-diene-8ß-ol (3) and/or guaianediol (4) and/or 1S,4R,5S-guia-6,9-dien-4-ol (5) and/or 3,4-epoxyguaia-10(12)-ene (6) and/or guaian-4,6-dien-10a-ol (7) and/or 8ß-hydroxyprespatane (8) and/or capillosanol (9), all of these sesquiterpenes were previously obtained from Nephthea chabrolii [20] [21] [19], except sesquiterpenes (6) and (8) were obtained from Nephthea sp. and Nephthea erecta respectively [22] [23]. Similarly, the mass ion peak at $m / z 234.161$ for the predicted molecular formula $\mathrm{C}_{15} \mathrm{H}_{22} \mathrm{O}_{2}$, was dereplicated as the sesquiterpenes; $1 \mathrm{a}$-hydroxy-(+)-cyclocolorenone (10), which was formerly characterized from Nephthea $s p$. [24]. Furthermore, the mass ion peak at $m / z 236.177$ in accordance with the molecular formula $\mathrm{C}_{15} \mathrm{H}_{24} \mathrm{O}_{2}$, was dereplicated as hydroxycolorenone (11) and/or $6 \beta, 7 \beta$-epoxy-4 $\beta$-hydroxyguaian-10-ene (12) and/or 3,4-epoxy-11-hydroxy-1-pseudoguaiene (13) and/or 8 $\beta$-hydroperoxyprespatane (14) and/or chabrolidione A (15) and/or (2E,6E)-3-isopropyl-6-methyl-10oxoundec-2,6-dienal (16), sesquiterpenes (11), (12) and (15) were previously obtained from Nephthea chabrolii [24] [19] [25], while sesquiterpenes (13), (14) and (16) were obtained from Nephthea erecta [19] [22] [26]. Moreover, the mass ion peak at $m / z 238.193$ in agreement with the molecular formula $\mathrm{C}_{15} \mathrm{H}_{26} \mathrm{O}_{2}$ was dereplicated as the sesquiterpenes; ent-oplopanone (17) and/or nephthediol (18), both of them were previously reported from Nephthea $s p$. [18]. Similarly, the mass ion peak at $m / z 240.172$ for the predicted molecular formula $\mathrm{C}_{14} \mathrm{H}_{24} \mathrm{O}_{3}$, was dereplicated as the sesquiterpenes; chabranol (19), which was formerly characterized from Nephthea chabrolii [23]. Moreover, the mass ion peak at $m / z 250.193$ in agreement 
with the molecular formula $\mathrm{C}_{16} \mathrm{H}_{26} \mathrm{O}_{2}$ was dereplicated as the sesquiterpenes; Methoxycolorenone (20) and/or 2-deoxy-7-0-methyllemnacarnol (21), the former was previously reported from Nephthea chabrolii [27], while the other was previously reported from Nephthea $s p$. [28]. Another compound was dereplicated as $10 a$-methoxy-4 $\beta$-hydroxy guaian-6-ene (22), on account of the observed mass ion peak at $\mathrm{m} / \mathrm{z}$ 252.208, and in accordance with the molecular formula $\mathrm{C}_{16} \mathrm{H}_{28} \mathrm{O}_{2}$, this sesquiterpene was formerly characterized from Nephthea chabrolii [19]. 
Table 1

A list of identified metabolites in soft coral Nephthea mollis.

\begin{tabular}{|c|c|c|c|c|c|}
\hline & Compound & Class & Rt & $\begin{array}{l}\text { Molecular } \\
\text { Formula }\end{array}$ & Mass \\
\hline 1 & Cadina-4(14),5-diene & Sesquiterpenes & 6.12 & $\mathrm{C}_{15} \mathrm{H}_{24}$ & 204.1875 \\
\hline 2 & 4,15-dihydro guaian-6,10-diene & Sesquiterpenes & 6.12 & $\mathrm{C}_{15} \mathrm{H}_{24}$ & 204.1879 \\
\hline 3 & Eudesma-4,7(11)-diene-8 $\beta$-ol & Sesquiterpenes & 4.73 & $\mathrm{C}_{15} \mathrm{H}_{24} \mathrm{O}$ & 220.183 \\
\hline 4 & Guaianediol & Sesquiterpenes & 4.73 & $\mathrm{C}_{15} \mathrm{H}_{24} \mathrm{O}$ & 220.183 \\
\hline 5 & 1S,4R,5S-guia-6,9-dien-4-ol & Sesquiterpenes & 4.73 & $\mathrm{C}_{15} \mathrm{H}_{24} \mathrm{O}$ & 220.183 \\
\hline 6 & 3,4-epoxyguaia-10(12)-ene & Sesquiterpenes & 4.73 & $\mathrm{C}_{15} \mathrm{H}_{24} \mathrm{O}$ & 220.183 \\
\hline 7 & guaian-4,6-dien-10 $a$-ol & Sesquiterpenes & 4.73 & $\mathrm{C}_{15} \mathrm{H}_{24} \mathrm{O}$ & 220.183 \\
\hline 8 & $8 \beta$-hydroxyprespatane & Sesquiterpenes & 4.73 & $\mathrm{C}_{15} \mathrm{H}_{24} \mathrm{O}$ & 220.183 \\
\hline 9 & Capillosanol & Sesquiterpenes & 4.73 & $\mathrm{C}_{15} \mathrm{H}_{24} \mathrm{O}$ & 220.183 \\
\hline 10 & $1 a$-hydroxy-(+)-cyclocolorenone & Sesquiterpenes & 2.99 & $\mathrm{C}_{15} \mathrm{H}_{22} \mathrm{O}_{2}$ & 234.1614 \\
\hline 11 & Hydroxycolorenone & Sesquiterpenes & 2.99 & $\mathrm{C}_{15} \mathrm{H}_{24} \mathrm{O}_{2}$ & 236.1774 \\
\hline 12 & $\begin{array}{l}6 \beta, 7 \beta \text {-Epoxy- } 4 \beta \text {-hydroxyguaian-10- } \\
\text { ene }\end{array}$ & Sesquiterpenes & 2.99 & $\mathrm{C}_{15} \mathrm{H}_{24} \mathrm{O}_{2}$ & 236.1774 \\
\hline 13 & $\begin{array}{l}\text { 3,4-epoxy-11-hydroxy-1- } \\
\text { pseudoguaiene }\end{array}$ & Sesquiterpenes & 2.99 & $\mathrm{C}_{15} \mathrm{H}_{24} \mathrm{O}_{2}$ & 236.1774 \\
\hline 14 & $8 \beta$-hydroperoxyprespatane & Sesquiterpenes & 2.99 & $\mathrm{C}_{15} \mathrm{H}_{24} \mathrm{O}_{2}$ & 236.1774 \\
\hline 15 & Chabrolidione A & Sesquiterpenes & 2.99 & $\mathrm{C}_{15} \mathrm{H}_{24} \mathrm{O}_{2}$ & 236.1774 \\
\hline 16 & $\begin{array}{l}\text { (2E,6E)-3-isopropyl-6-methyl-10- } \\
\text { oxoundec -2,6-dienal }\end{array}$ & Sesquiterpenes & 2.99 & $\mathrm{C}_{15} \mathrm{H}_{24} \mathrm{O}_{2}$ & 236.1774 \\
\hline 17 & Ent-oplopanone & Sesquiterpenes & 4.72 & $\mathrm{C}_{15} \mathrm{H}_{26} \mathrm{O}_{2}$ & 238.1934 \\
\hline 18 & Nephthediol & Sesquiterpenes & 4.72 & $\mathrm{C}_{15} \mathrm{H}_{26} \mathrm{O}_{2}$ & 238.1934 \\
\hline 19 & Chabranol & Sesquiterpenes & 4.50 & $\mathrm{C}_{14} \mathrm{H}_{24} \mathrm{O}_{3}$ & 240.1727 \\
\hline 20 & Methoxycolorenone & Sesquiterpenes & 5.21 & $\mathrm{C}_{16} \mathrm{H}_{26} \mathrm{O}_{2}$ & 250.1932 \\
\hline 21 & 2-deoxy-7-O-methyllemnacarnol & Sesquiterpenes & 5.21 & $\mathrm{C}_{16} \mathrm{H}_{26} \mathrm{O}_{2}$ & 250.1932 \\
\hline
\end{tabular}




\begin{tabular}{|c|c|c|c|c|c|}
\hline & Compound & Class & Rt & $\begin{array}{l}\text { Molecular } \\
\text { Formula }\end{array}$ & Mass \\
\hline 22 & $\begin{array}{l}10 \alpha \text {-methoxy- } 4 \beta \text {-hydroxy guaian- } 6 \text { - } \\
\text { ene }\end{array}$ & Sesquiterpenes & 5.01 & $\mathrm{C}_{16} \mathrm{H}_{28} \mathrm{O}_{2}$ & 252.2085 \\
\hline 23 & Nephtheoxydiol & Sesquiterpenes & 5.11 & $\mathrm{C}_{15} \mathrm{H}_{26} \mathrm{O}_{3}$ & 254.1878 \\
\hline 24 & $\begin{array}{l}\text { 1S-acetoxygermacra-3Z,5E,10(15)- } \\
\text { triene }\end{array}$ & Sesquiterpenes & 5.41 & $\mathrm{C}_{17} \mathrm{H}_{26} \mathrm{O}_{2}$ & 262.1932 \\
\hline 25 & Armatin E & Sesquiterpenes & 5.41 & $\mathrm{C}_{16} \mathrm{H}_{24} \mathrm{O}_{3}$ & 264.1718 \\
\hline 26 & $4 a-O$-acetyl-selin-11-en & Sesquiterpenes & 5.41 & $\mathrm{C}_{17} \mathrm{H}_{28} \mathrm{O}_{2}$ & 264.2088 \\
\hline 27 & $\begin{array}{l}\text { 2-deoxy-12-ethoxy-7-0-methyl } \\
\text { lemnacarnol }\end{array}$ & Sesquiterpenes & 5.99 & $\mathrm{C}_{18} \mathrm{H}_{30} \mathrm{O}_{3}$ & 294.2187 \\
\hline 28 & Ketochabrolic acid & $\begin{array}{l}\text { Terpenoid-related } \\
\text { carboxylic acids }\end{array}$ & 2.95 & $\mathrm{C}_{18} \mathrm{H}_{28} \mathrm{O}_{3}$ & 292.2032 \\
\hline 29 & Isoketochabrolic acid & $\begin{array}{l}\text { Terpenoid-related } \\
\text { carboxylic acids }\end{array}$ & 2.95 & $\mathrm{C}_{18} \mathrm{H}_{28} \mathrm{O}_{3}$ & 292.2032 \\
\hline 30 & Chabrolol A & Diterpenes & 5.41 & $\mathrm{C}_{17} \mathrm{H}_{28} \mathrm{O}_{2}$ & 264.2088 \\
\hline 31 & Brassicolide & Diterpenes & 5.65 & $\mathrm{C}_{20} \mathrm{H}_{30} \mathrm{O}_{3}$ & 318.2202 \\
\hline 32 & Brassicolene & Diterpenes & 5.73 & $\mathrm{C}_{22} \mathrm{H}_{32} \mathrm{O}_{2}$ & 328.2408 \\
\hline 33 & Nephthenol & Diterpenes & 2.99 & $\mathrm{C} 2 \mathrm{OH} 340$ & 290.260 \\
\hline
\end{tabular}

\subsection{Molecular docking}

For further exploration and getting a better idea about the possible target affected by dereplicated compounds of Nephthea mollis to afford their anti-trypanosomal activity, we performed in-silico molecular docking [2] simulations within ornithine decarboxylase (ORD). The X-ray structure of ORD showed to ligands; D-Ornithine, ORX, a substrate analog and was placed within ORD active site and Geneticin (G418) as a weak non-competitive inhibitor occupying allosteric site of ORD. Molecular docking simulations performed within the active site of ORD should number of binding interactions (H-bonding and $\mathrm{H}$-pi interactions) between ORX and a number of amino acid residues (GLU 274, ASP 332, GLY 276, ARG 277, TYR 389, GLY 237, and HIS 197) with binding free energy (S) of $-4.5058 \mathrm{kcal} / \mathrm{mol}$, (Fig. 5). On the other hand, five of the identified compounds (2-deoxy-12-ethoxy-7-O-methyl lemnacarnol, Nephthenol, 4a-O-acetyl-selin-11-en, Eudesma-4,7(11)-diene-8 $\beta$-ol, and Chabrolidione A) showed a better binding interaction with binding free energy lower than that found with the substrate analog, ORX, (Table 2). 
Table 2

Binding free energy ( $\mathrm{S} ; \mathrm{kcal} / \mathrm{mol}$ ) and binding accuracy (RMSD; $\AA$ ) of Nephthea mollis and co-crystallized ligand within ornithine decarboxylase (ORD) active site (PDB ID: 1NJJ; $2.45 \AA$ )

\begin{tabular}{|c|c|c|}
\hline Molecule & $\begin{array}{l}\text { Energy score } \\
\text { (S; kcal/mol) }\end{array}$ & $\operatorname{RMSD}(\AA ̊)$ \\
\hline INJJ Co-crystallized ligand (ORX) & -4.5058 & 1.8918 \\
\hline 2-deoxy-12-ethoxy-7-O-methyl lemnacarnol & -5.2186 & 2.0242 \\
\hline Nephthenol & -4.8930 & 1.8370 \\
\hline 4a-O-acetyl-selin-11-en & -4.6440 & 1.9708 \\
\hline Eudesma-4,7(11)-diene-8ß-ol & -4.5653 & 0.6331 \\
\hline Chabrolidione A & -4.5278 & 0.9897 \\
\hline Guaian-4,6-dien-10a-ol & -4.4267 & 1.6648 \\
\hline Brassicolide & -4.4262 & 1.8294 \\
\hline Capillosanol & -4.2383 & 2.2662 \\
\hline Chabrolol A & -4.2271 & 1.8498 \\
\hline Nephtheoxydiol & -4.1673 & 1.4596 \\
\hline 1a-hydroxy-(+)-cyclocolorenone & -4.0963 & 1.3961 \\
\hline 1 Sacetoxygermacra-3Z,5E,10(15)-triene & -4.0880 & 0.9902 \\
\hline $8 \beta$-hydroperoxyprespatane & -4.0673 & 1.5743 \\
\hline 3,4-epoxyguaia-10(12)-ene & -4.0394 & 1.7450 \\
\hline 2-deoxy-7-0-methyllemnacarnol & -4.0057 & 1.4953 \\
\hline 4,15-dihydroguaian-6,10-diene & -3.9922 & 1.9155 \\
\hline 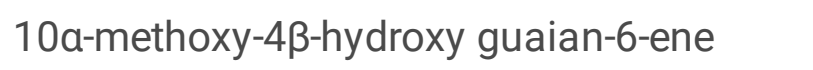 & -3.9431 & 1.8772 \\
\hline $8 \beta$-hydroxyprespatane & -3.8998 & 1.5906 \\
\hline $6 \beta, 7 \beta$-Epoxy-4 $\beta$-hydroxyguaian-10-ene & -3.8558 & 2.0234 \\
\hline Methoxycolorenone & -3.7555 & 2.1270 \\
\hline Chabranol & -3.7507 & 1.6197 \\
\hline Hydroxycolorenone & -3.5285 & 2.1016 \\
\hline Nephthediol & -3.4163 & 2.4168 \\
\hline Cadina-4(14),5-diene & -3.4067 & 2.4022 \\
\hline
\end{tabular}




\begin{tabular}{|lll|}
\hline Molecule & $\begin{array}{l}\text { Energy score } \\
(\mathbf{S} ; \mathrm{kcal} / \mathrm{mol})\end{array}$ & $\mathrm{RMSD}(\AA)$ \\
\hline Armatin E & -3.3336 & 2.1020 \\
\hline Ent-oplopanone & -2.8246 & 2.3728 \\
\hline Brassicolene & -2.7567 & 2.5090 \\
\hline 1S,4R,5S-guia-6,9-dien-4-ol & -2.0255 & 1.1860 \\
\hline
\end{tabular}

Moreover, most of the remaining compounds were almost equal to ORX binding free energy or a little bit lower, as listed in Table 2. 6,7-epoxy-4-hydroxyguaian-10-ene, chabrolidione A, and nephtheoxydiol showed a good overlay with co-crystallized ligand ORX within ORD active site (Fig. 4).

Furtherly, visual inspection of the resultant docking poses of each compound showed a number of binding interactions (varying from $\mathrm{H}$-bonding to $\mathrm{H}$-pi interactions) between some of the dereplicated compounds and various amino acids lining ORD active site similar to that found with ORX, (Table 3; Fig. 5). All in all, the obtained molecular docking data showed how good the overlay of the dereplicated compounds of Nephthea mollis within ornithine decarboxylase (ORD) active site, which could explain their anti-trypanosomal activity against Trypanosoma brucei. 
Table 3

Binding free energy $(\mathrm{S} ; \mathrm{kcal} / \mathrm{mol})$ and binding interactions for co-crystallized ligand (ORX) and Nephthea mollis within ornithine decarboxylase (ORD) active site (PDB ID: 1NJJ; $2.45 \AA$ )

\begin{tabular}{|c|c|c|c|c|}
\hline \multirow[t]{2}{*}{ Ligand } & \multirow{2}{*}{$\begin{array}{l}\text { Binding } \\
\text { energy } \\
\text { score } \\
\text { (S; } \\
\text { kcal/mol) }\end{array}$} & \multicolumn{3}{|c|}{ Ligand - active site interactions } \\
\hline & & $\begin{array}{l}\text { a. a. } \\
\text { residue }\end{array}$ & Bond type & $\begin{array}{l}\text { Bond length } \\
(\AA)\end{array}$ \\
\hline \multirow{9}{*}{$\begin{array}{l}\text { Co-crystallized } \\
\text { Ligand (ORX) }\end{array}$} & \multirow{9}{*}{-4.5058} & GLU 274 & H-donor & 3.16 \\
\hline & & ASP 332 & H-donor & 3.30 \\
\hline & & GLY 276 & $\begin{array}{l}\mathrm{H}- \\
\text { acceptor }\end{array}$ & 2.92 \\
\hline & & ARG 277 & $\begin{array}{l}\mathrm{H}- \\
\text { acceptor }\end{array}$ & 2.74 \\
\hline & & TYR 389 & $\begin{array}{l}\mathrm{H}- \\
\text { acceptor }\end{array}$ & 2.55 \\
\hline & & GLY 237 & $\begin{array}{l}\mathrm{H}- \\
\text { acceptor }\end{array}$ & 2.70 \\
\hline & & GLY 276 & $\begin{array}{l}\mathrm{H}- \\
\text { acceptor }\end{array}$ & 3.07 \\
\hline & & TYR 389 & $H-p i$ & 3.71 \\
\hline & & HIS 197 & Pi-pi & 3.88 \\
\hline \multirow[t]{2}{*}{$8 \beta$-hydroxyprespatane } & \multirow[t]{2}{*}{-3.8998} & ARG 154 & $\begin{array}{l}\mathrm{H}- \\
\text { acceptor }\end{array}$ & 2.91 \\
\hline & & ARG 154 & $\begin{array}{l}\mathrm{H}- \\
\text { acceptor }\end{array}$ & 3.17 \\
\hline Capillosanol & -4.2383 & HIS 197 & $H-p i$ & 4.36 \\
\hline 1a-hydroxy-(+)-cyclocolorenone & -4.0963 & HIS 197 & $H-p i$ & 3.98 \\
\hline Hydroxycolorenone & -3.5285 & LYS 69 & $\begin{array}{l}\mathrm{H} \text { - } \\
\text { acceptor }\end{array}$ & 3.11 \\
\hline \multirow[t]{2}{*}{ 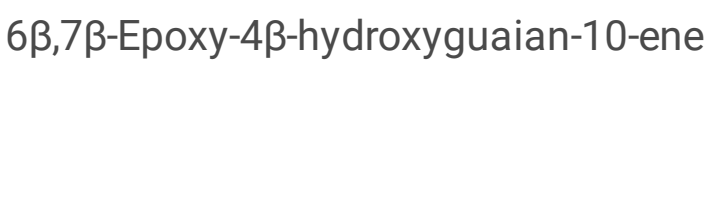 } & \multirow[t]{2}{*}{-3.8558} & LYS 69 & $\begin{array}{l}\mathrm{H}- \\
\text { acceptor }\end{array}$ & 2.95 \\
\hline & & HIS 197 & H-pi & 3.97 \\
\hline $8 \beta$-hydroperoxyprespatane & -4.0673 & LYS 69 & $\begin{array}{l}\mathrm{H}- \\
\text { acceptor }\end{array}$ & 3.31 \\
\hline Chabranol & -3.7507 & ARG 277 & $\begin{array}{l}\mathrm{H}- \\
\text { acceptor }\end{array}$ & 2.91 \\
\hline
\end{tabular}




\begin{tabular}{|c|c|c|c|c|}
\hline \multirow[t]{2}{*}{ Ligand } & \multirow{2}{*}{$\begin{array}{l}\text { Binding } \\
\text { energy } \\
\text { score } \\
\text { (S; } \\
\text { kcal/mol) }\end{array}$} & \multicolumn{3}{|c|}{ Ligand - active site interactions } \\
\hline & & $\begin{array}{l}\text { a. a. } \\
\text { residue }\end{array}$ & Bond type & $\begin{array}{l}\text { Bond length } \\
(\AA)\end{array}$ \\
\hline & & HIS 197 & H-pi & 3.85 \\
\hline \multirow[t]{3}{*}{ Chabrolidione A } & -4.5278 & LYS 69 & $\begin{array}{l}\mathrm{H}- \\
\text { acceptor }\end{array}$ & 2.94 \\
\hline & & ARG 277 & $\begin{array}{l}\mathrm{H}- \\
\text { acceptor }\end{array}$ & 2.92 \\
\hline & & SER 200 & $\begin{array}{l}\mathrm{H}- \\
\text { acceptor }\end{array}$ & 3.06 \\
\hline $\begin{array}{l}\text { 1S-acetoxygermacra-3Z,5E,10(15)- } \\
\text { triene }\end{array}$ & -4.0880 & GLU 274 & H-donor & 3.31 \\
\hline Chabrolol A & -4.2271 & GLU 274 & H-donor & 2.71 \\
\hline Nephthenol & -4.8930 & ARG 277 & $\begin{array}{l}\mathrm{H}- \\
\text { acceptor }\end{array}$ & 2.79 \\
\hline Nephthediol & -3.4163 & LYS 69 & $\begin{array}{l}\mathrm{H}- \\
\text { acceptor }\end{array}$ & 3.26 \\
\hline
\end{tabular}

\section{Material And Methods 3.1. Soft coral material}

The soft coral Nephthea mollis (Kingdom: Animalia, Phylum: Cnidaria, Class: Anthozoa, Subclass: Octocorallia, Order: Alcyonacea, Family: Nephtheidae) was collected by Prof. Mohamed A. Abu El-Regal, Professor of Biological Oceanography, Marine Biology Department, Faculty of Marine Science, King Abdulaziz University, Jeddah, Saudi Arabia by scuba diving from the coasts of Hurgada, Egypt, at a depth of $12 \mathrm{~m}$ in March 2018. It was then stored at $-20^{\circ} \mathrm{C}$ until investigation. A voucher specimen was kept in the herbarium of Pharmacognosy Department, Faculty of Pharmacy, Minia University, Minia, Egypt under registration number Mn-Ph-Cog-47.

\subsection{Chemicals and reagents}

Organic solvents used in this study, including ethanol, ethyl acetate, and petroleum ether (b.p. $60-80^{\circ} \mathrm{C}$ ) were of analytical grade and distilled before use. All these solvents were purchased from El-Nasr Company for Pharmaceuticals and Chemicals, Egypt. Solvents of HPLC grade such as acetonitrile and methanol were obtained from SDFCL sd fine-Chem Limited, India.

\subsection{Extract preparation}


The freeze-dried soft coral material $(45 \mathrm{~g})$ was extracted with ethanol until exhaustion. The concentrated organic extract ( $15 \mathrm{~g}$ ) was suspended in distilled water and extracted successively with different organic solvents, including petroleum ether, and ethyl acetate. The organic phase in each step was separately concentrated under vacuum, yielding the petroleum ether fraction $(6 \mathrm{~g})$, the ethyl acetate fraction $(1 \mathrm{~g})$, and the aqueous fraction $(8 \mathrm{~g})$. The total ethanol extract and its derived fractions; petroleum ether and ethyl acetate were kept at $4^{\circ} \mathrm{C}$ for anti-trypanosomal assay and other analysis.

\subsection{In-vitro anti-trypanosomal activity (Huber and Koella assay)}

The anti-trypanosomal potential was tested against Trypanosoma brucei following the protocol of Huber and Koella [32]. A number of $10^{4}$ trypanosomes per ml of Trypanosoma brucei strain TC221 was cultivated in a complete Baltz medium. Trypanosomes were tested in 96-well plate chambers against different concentrations of test extracts at $10-200 \mu \mathrm{g} / \mathrm{ml}$ in $1 \%$ DMSO to a final volume of $200 \mu \mathrm{L}$. For control, $1 \%$ DMSO, as well as parasites without any test extracts, were used simultaneously in each plate to show an absence of any activity due to $1 \%$ DMSO. The plates were then incubated at $37^{\circ} \mathrm{C}$ in an atmosphere of $5 \% \mathrm{CO}_{2}$ for $24 \mathrm{~h}$. After the addition of $20 \mu \mathrm{l}$ of Alamar Blue, the activity was measured after 48 and $72 \mathrm{~h}$ by light absorption using MR 700 microplate reader at a wavelength of $550 \mathrm{~nm}$ with a reference wavelength of $650 \mathrm{~nm}$. IC $\mathrm{C}_{50}$ values of the tested extracts were quantified by linear interpolation of three independent measurements [33, 34].

\subsection{LC-MS Metabolomic profiling}

Metabolomic profiling of the total ethanol extract of Nephthea mollis was carried out as described by Abdelmohsen et al. [35] using an Acquity Ultra Performance Liquid Chromatography system connected to a Synapt G2 HDMS quadrupole timeof-flight hybrid mass spectrometer (Waters, Milford, USA). Chromatographic separation was carried out using a BEH C18 column $(2.1 \times 100 \mathrm{~mm}, 1.7 \mu \mathrm{m}$ particle size; Waters, Milford, USA) accompanied with a guard column $(2.1 \times 5 \mathrm{~mm}, 1.7 \mu \mathrm{m}$ particle size $)$. The mobile phase used during the separation consisted of purified water $(A)$ and acetonitrile $(B)$ with $0.1 \%$ formic acid added to each solvent. A gradient elution started at a flow rate of $300 \mu \mathrm{L} / \mathrm{min}$ with $10 \% \mathrm{~B}$ linearly increased to $100 \%$ B within 30 min and remained isocratic for the next 5 min before linearly decreasing back to $10 \% \mathrm{~B}$ for the following $1 \mathrm{~min}$. The volume injected was $2 \mu \mathrm{L}$ and the column temperature was adjusted to $40^{\circ} \mathrm{C}$. The obtained raw data were separated into positive and negative ionization mode using MSConvert software. Accordingly, the files were imported to the data mining software MZmine 2.10 for peak picking followed by deconvolution, deisotoping, alignment, and formula prediction. The Dictionary of Natural Products (DNP), METLIN, and Marinlit databases were used for the identification of compounds. [36] [37].

\subsection{Molecular docking}

In-Silico molecular docking simulations for dereplicated compounds of Nephthea mollis within ornithine decarboxylase (PDB ID: 1NJJ) active site were performed. RCS PDB deposited crystal structure resolution 
was $2.45 \AA$ was used as a PDB entry for ornithine decarboxylase since it was co-crystallized with a small molecule natural substrate capable of stimulating activity of ornithine decarboxylase in a biochemical and cell-based assay. Structures of dereplicated compounds were prepared in ChemDraw ${ }^{\circledR}$ Ultra (v. 8, 2013) and were transferred as smiles to Builder software embedded in molecular orbital environment (MOE; 09-2014) software and their energy were minimized. Proteins structures' were also prepared according to MOE LigX protocol and their structures were protonated at a cut-off value of $15 \AA$. Validation of docking process of co-crystallized ligand (ornithine ORX) and MD simulations of all test compounds from Nephthea mollis were done by triangular placement method and London $\delta G$ for rescoring 1 for only 10 retained docking poses of each compound. The resultant docking poses for each compound were examined and arranged according to their free binding energy value (S; Kcal/mol) and docking accuracy resolution (RMSD; $\AA$ ) $[15,16]$.

\section{Conclusion}

The current study highlighted the anti-trypanosomal potential of the total extract and different fractions of the soft coral Nephthea mollis where the total ethanol extract and its derived ethyl acetate fraction displayed remarkable in-vitro anti-trypanosomal potential against Trypanosoma brucei. Such effects are likely underlain by the availability of a range of compounds, mostly sesquiterpenes, and diterpenes that were mined with the help of LC-MS-based metabolomics. Docking studies of the identified compounds postulated their mechanism of action, which was further evidenced by in-vitro assays.

\section{Declarations}

\section{Conflicts of interest}

The authors declare no conflict of interest.

\section{References}

1. Berriman M, Ghedin E, Hertz-Fowler C, Blandin G, Renauld H, Bartholomeu DC et al. The genome of the African trypanosome Trypanosoma brucei. 2005;309(5733):416-22.

2. Mahmoud BK, Hamed ANE, Samy MN, Abdelmohsen UR, Attia EZ, Fawzy MA et al. Metabolomic profiling and biological investigation of Tabebuia Aurea (Silva Manso) leaves, family Bignoniaceae. 2019:1-6.

3. Jacob M, Lopata AL, Dasouki M, Abdel Rahman AMJMsr. Metabolomics toward personalized medicine. 2019;38(3):221-38.

4. Said AAE, Afifi AH, Ali TF, Samy MN, Abdelmohsen UR, Fouad MA et al. NS3/4A helicase inhibitory alkaloids from Aptenia cordifolia as HCV target. 2021;11(52):32740-9.

5. Bakr RO, Tawfike A, El-Gizawy HA, Tawfik N, Abdelmohsen UR, Abdelwahab MF et al. The metabolomic analysis of five Mentha species: cytotoxicity, anti-Helicobacter assessment, and the 
development of polymeric micelles for enhancing the anti-Helicobacter activity. 2021;11(13):7318-30.

6. Abdelmohsen UR, Cheng C, Viegelmann C, Zhang T, Grkovic T, Ahmed S et al. Dereplication strategies for targeted isolation of new antitrypanosomal actinosporins $A$ and $B$ from a marine sponge associated-Actinokineospora sp. EG49. 2014;12(3):1220-44.

7. Yuliana ND, Khatib A, Choi YH, Verpoorte RJPR. Metabolomics for bioactivity assessment of natural products. 2011;25(2):157-69.

8. Tawfike AF, Viegelmann C, Edrada-Ebel R. Metabolomics and dereplication strategies in natural products. Metabolomics Tools for Natural Product Discovery. Springer; 2013. p. 227-44.

9. Kjer J, Debbab A, Aly AH, Proksch PJNp. Methods for isolation of marine-derived endophytic fungi and their bioactive secondary products. 2010;5(3):479-90.

10. Lotfy MM, Sayed AM, AboulMagd AM, Hassan HM, El Amir D, Abouzid SF et al. Metabolomic profiling, biological evaluation of Aspergillus awamori, the river Nile-derived fungus using epigenetic and OSMAC approaches. 2021;11(12):6709-19.

11. Blackman A, Bowden B, Coll J, Frick B, Mahendran M, Mitchell SJAJoC. Studies of Australian soft corals. XXIX. Several new cembranoid diterpenes from Nephthea brassica and related diterpenes from a Sarcophyton species. 1982;35(9):1873-80.

12. Cheng S-Y, Huang Y-C, Wen Z-H, Chiou S-F, Wang S-K, Hsu C-H et al. Novel sesquiterpenes and norergosterol from the soft corals Nephthea erecta and Nephthea chabroli. 2009;50(7):802-6.

13. Schmitz FJ, Vanderah DJ, Ciereszko LJJotCS, Chemical Communications. Marine natural products: nephthenol and epoxynephthenol acetate, cembrene derivatives from a soft coral. 1974(10):407-8.

14. Allam KM, Khedr Al, Allam AE, Abdelkader MSA, Elkhayat ES, Fouad MAJJoaB et al. Chemical and Biological Diversity in Nephthea Soft Corals in the Current Decade: A Review. 2021.

15. Jackson LK, Goldsmith EJ, Phillips MAJJoBC. X-ray structure determination of Trypanosoma brucei ornithine decarboxylase bound to D-ornithine and to G418: insights into substrate binding and ODC conformational flexibility. 2003;278(24):22037-43.

16. Hisham Shady N, Elfakharany Z, Salem MA, Ahmed S, Fouad MA, Salah Kamel M et al. Dereplication Analysis and Antitrypanosomal Potential of the Red Sea Sponge Amphimedon sp. Supported by Molecular Modelling. 2020.

17. Macintyre L, Zhang T, Viegelmann C, Martinez IJ, Cheng C, Dowdells $C$ et al. Metabolomic tools for secondary metabolite discovery from marine microbial symbionts. 2014;12(6):3416-48.

18. Kitagawa I, Cui Z, Son BW, KOBAYASHI M, KYOGOKU YJC, bulletin p. Marine natural products. XVII. Nephtheoxydiol, a new cytotoxic hydroperoxy-germacrane sesquiterpene, and related sesquiterpenoids from an Okinawan soft coral of Nephthea sp.(Nephtheidae). 1987;35(1):124-35.

19. Rao MR, Sridevi K, Venkatesham U, Rao TP, Lee S, Venkateswarlu YJJoCR. Four new sesquiterpenoids from the soft coral Nephthea chabrollii. 2000;2000(5):245-7.

20. Amir F, Koay YC, Yam WSJTJoPR. Chemical constituents and biological properties of the marine soft coral Nephthea: a review (Part 2). 2012;11(3):499-517. 
21. Tanod WA, Aristawati AT, Muliadin MJO-A. Soft Coral (Sinularia sp.) Extracts with Antibacterial Activity. 2018;14(1):108-17.

22. Cheng S-Y, Dai C-F, Duh C-YJJonp. Sesquiterpenoids and artificial 19-oxygenated steroids from the Formosan soft coral Nephthea erecta. 2007;70(9):1449-53.

23. Cheng S-Y, Huang K-J, Wang S-K, Wen Z-H, Hsu C-H, Dai C-F et al. New terpenoids from the soft corals Sinularia capillosa and Nephthea chabroli. 2009;11(21):4830-3.

24. Hu J, Yang B, Lin X, Zhou X, Yang X, Long $L$ et al. Chemical and biological studies of soft corals of the Nephtheidae family. 2011;8(6):1011-32.

25. Su J-H, Dai C-F, Huang H-H, Wu Y-C, Sung P-J, Hsu C-H et al. Terpenoid-related metabolites from a Formosan soft coral Nephthea chabrolii. 2007;55(4):594-7.

26. Abdelhafez OH, Ali TFS, Fahim JR, Desoukey SY, Ahmed S, Behery FA et al. Anti-inflammatory potential of green synthesized silver nanoparticles of the soft coral Nephthea sp. supported by metabolomics analysis and docking studies. 2020;15:5345.

27. Handayani D, Edrada RA, Proksch P, Wray V, Witte L, van Ofwegen L et al. New oxygenated sesquiterpenes from the Indonesian soft coral Nephthea chabrolii. 1997;60(7):716-8.

28. Kapojos MM, Mangindaan REP, Nakazawa T, Oda T, Ukai K, Namikoshi MJC et al. Three new nardosinane type sesquiterpenes from an Indonesian soft coral Nephthea sp. 2008;56(3):332-4.

29. Zhang W-H, Williams ID, Che C-TJTL. Chabrolols A, B and C, three new norditerpenes from the soft coral Nephthea chabroli. 2001;42(28):4681-5.

30. El-Gamal AA, Wang S-K, Dai C-F, Duh C-YJJonp. New Nardosinanes and 19-0xygenated Ergosterols from the Soft Coral Nephthea a rmata Collected in Taiwan. 2004;67(9):1455-8.

31. Duh C-Y, Wang S-K, Weng Y-L, Chiang MY, Dai C-FJJoNP. Cytotoxic terpenoids from the Formosan soft coral Nephthea brassica. 1999;62(11):1518-21.

32. Huber W, Koella JCJAt. A comparison of three methods of estimating EC50 in studies of drug resistance of malaria parasites. 1993;55(4):257-61.

33. Abdelmohsen UR, Pimentel-Elardo SM, Hanora A, Radwan M, Abou-El-Ela SH, Ahmed S et al. Isolation, phylogenetic analysis and anti-infective activity screening of marine sponge-associated actinomycetes. 2010;8(3):399-412.

34. Cos P, Vlietinck AJ, Berghe DV, Maes LJJoe. Anti-infective potential of natural products: how to develop a stronger in vitro 'proof-of-concept'. 2006;106(3):290-302.

35. Elmaidomy AH, Mohammed R, M Hassan H, I Owis A, E Rateb M, A Khanfar M et al. Metabolomic profiling and cytotoxic tetrahydrofurofuran lignans investigations from Premna odorata Blanco. 2019;9(10):223.

36. Helfrich EJ, Vogel CM, Ueoka R, Schäfer M, Ryffel F, Müller DB et al. Bipartite interactions, antibiotic production and biosynthetic potential of the Arabidopsis leaf microbiome. 2018;3(8):909-19.

37. Ancheeva E, Daletos G, Proksch PJMd. Lead compounds from mangrove-associated microorganisms. 2018;16(9):319. 
Figures

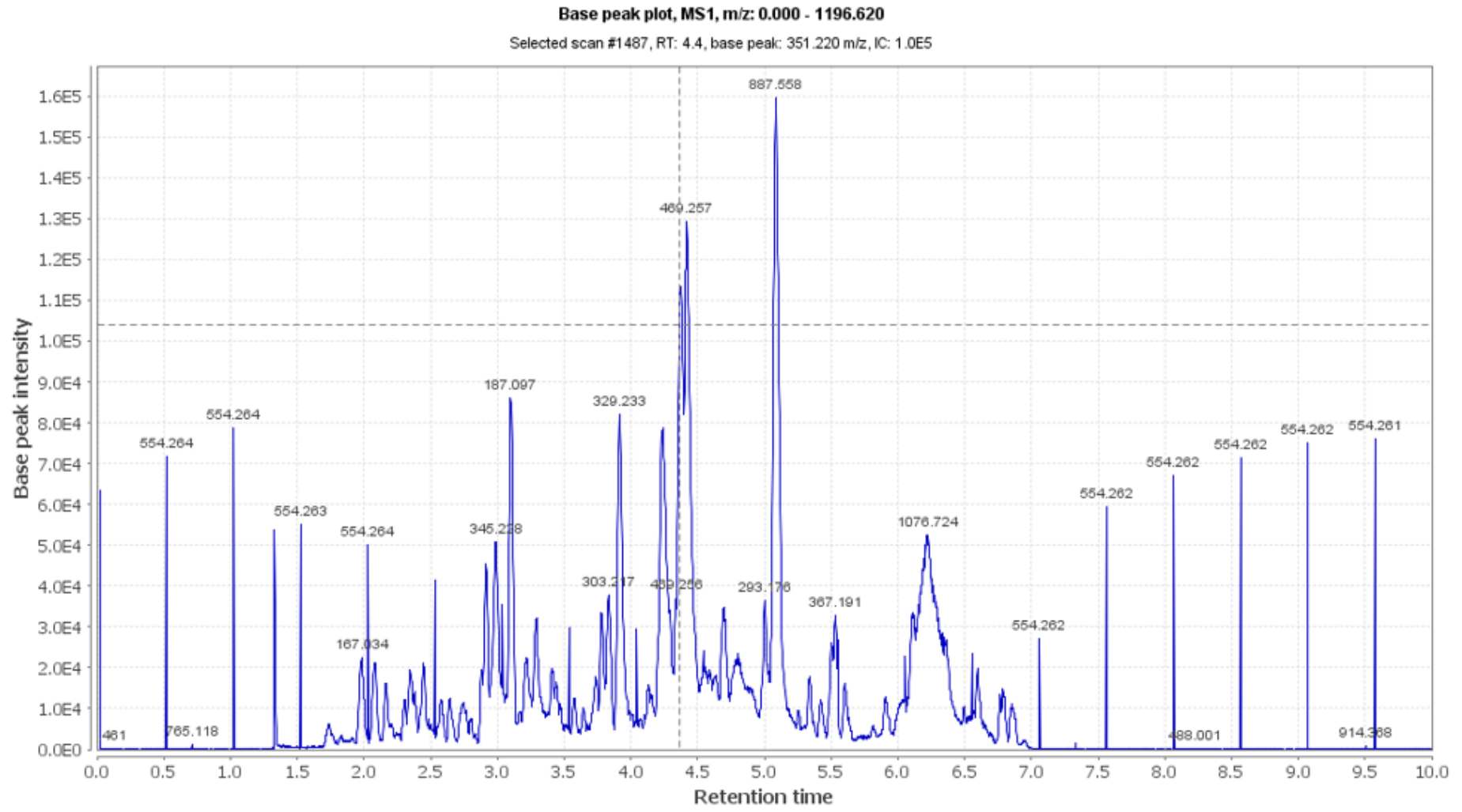

Figure 1

Total ion chromatogram of total extract of Nephthea mollis (Negative mood). 


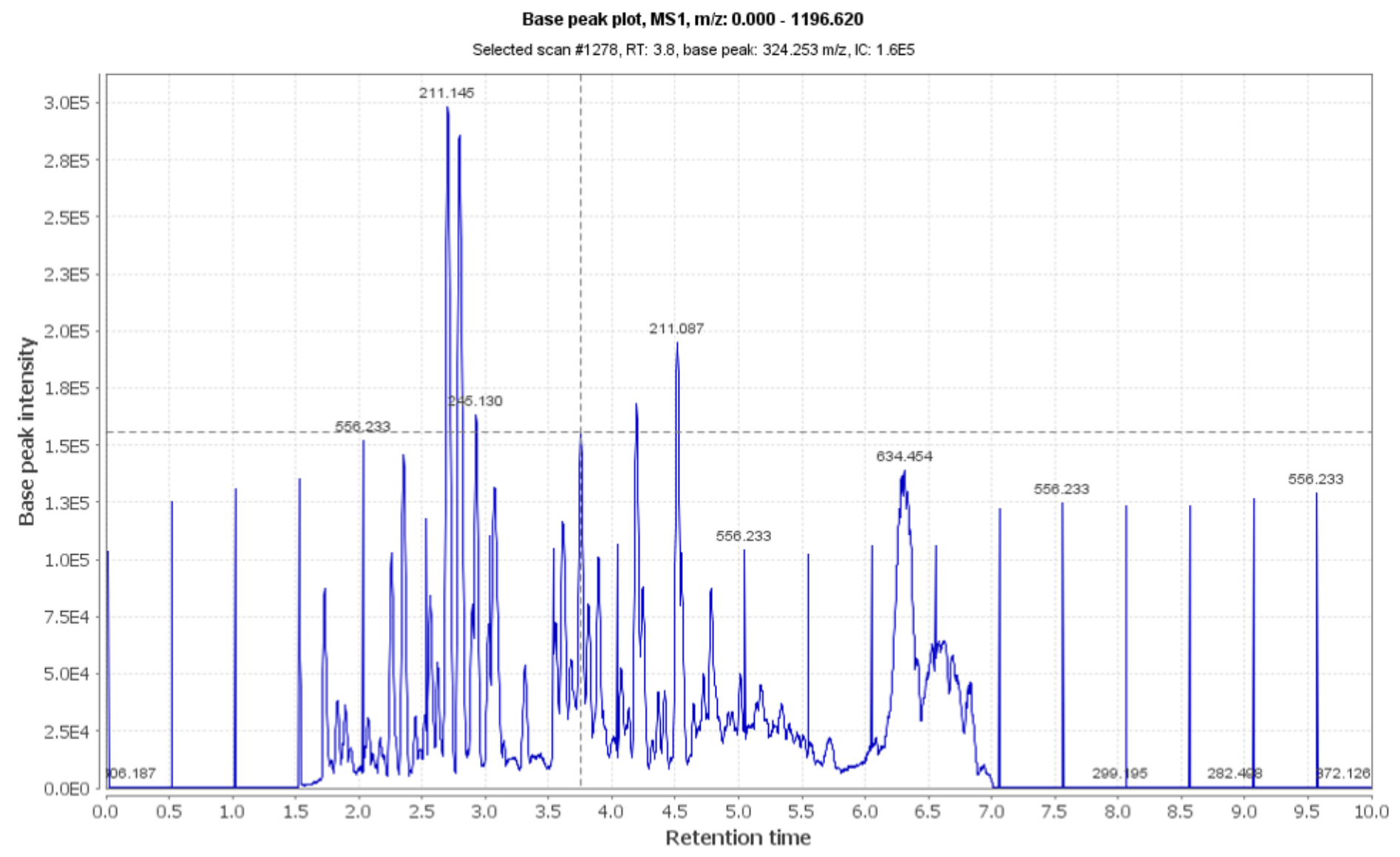

Figure 2

Total ion chromatogram of total extract of Nephthea mollis (Positive mood). 
So
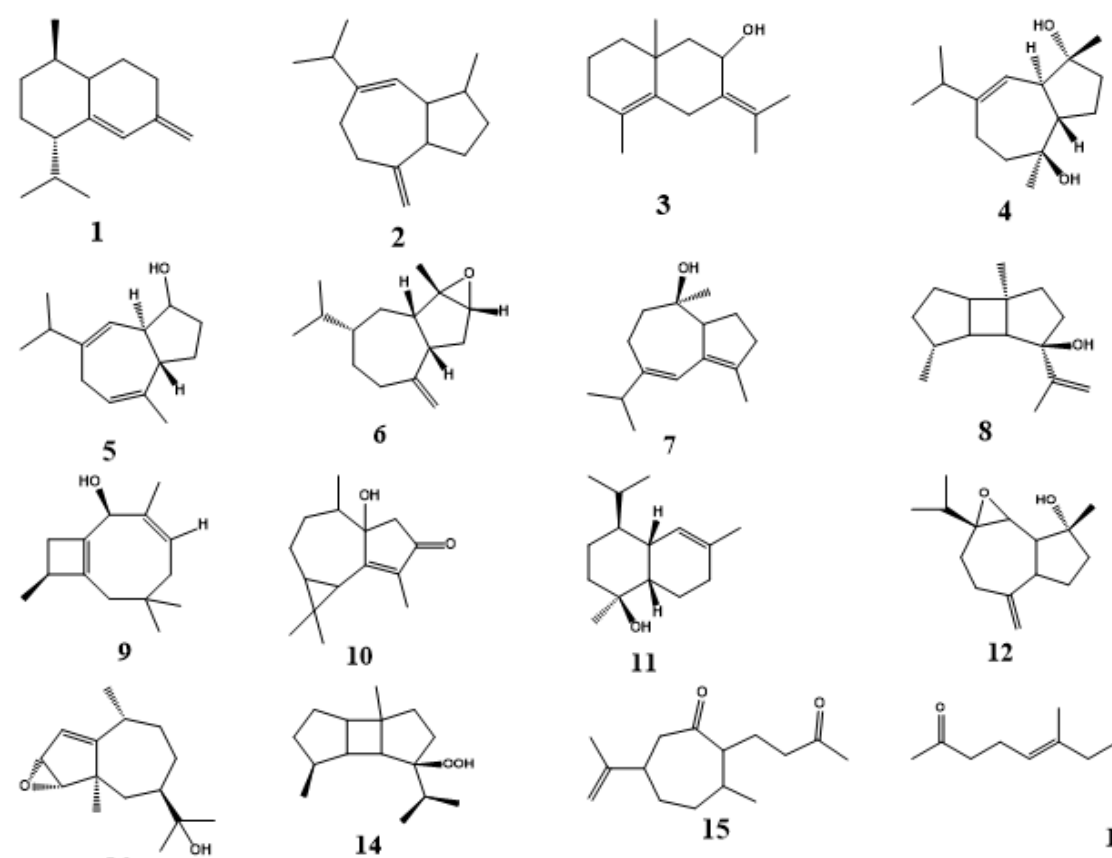

12

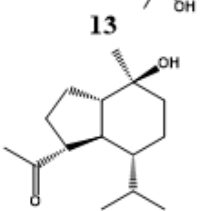

17<smiles>CO[C@]12CCC3=CCC[C@H](C)[C@]3(C)C1[C@@H](C)CO2</smiles>

21

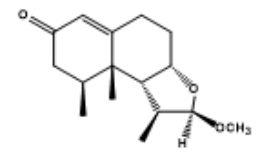

25<smiles>CC(C)C(C)CCC(/C=C\CC(C)(C)C)C(C)C</smiles>

18

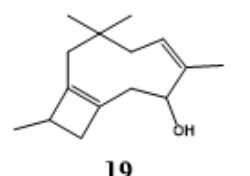

19
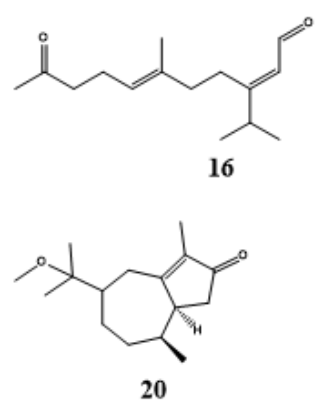<smiles>CC(C)C1CCC(=O)C23CCC(C)(C)CCC12C3</smiles>

23

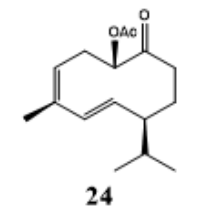<smiles>CCCC1C(C)C2C(C)CCC3=CCCC(C)C32C1CC</smiles>

27

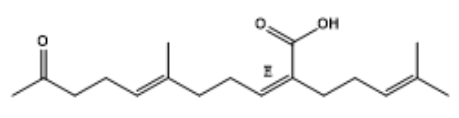

28

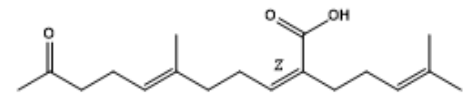

29

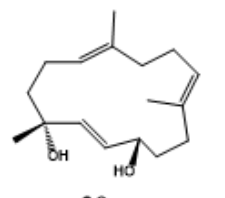

30

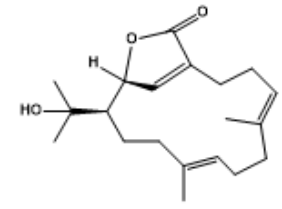

31

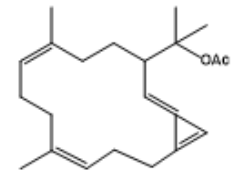

32<smiles>C/C=C(\C)CC/C=C(\C)CC/C=C(\C)CCC(C/C=C(/C)CC)C(C)(C)O</smiles>

\section{Figure 3}

Chemical structure of dereplicated compounds 1-33 

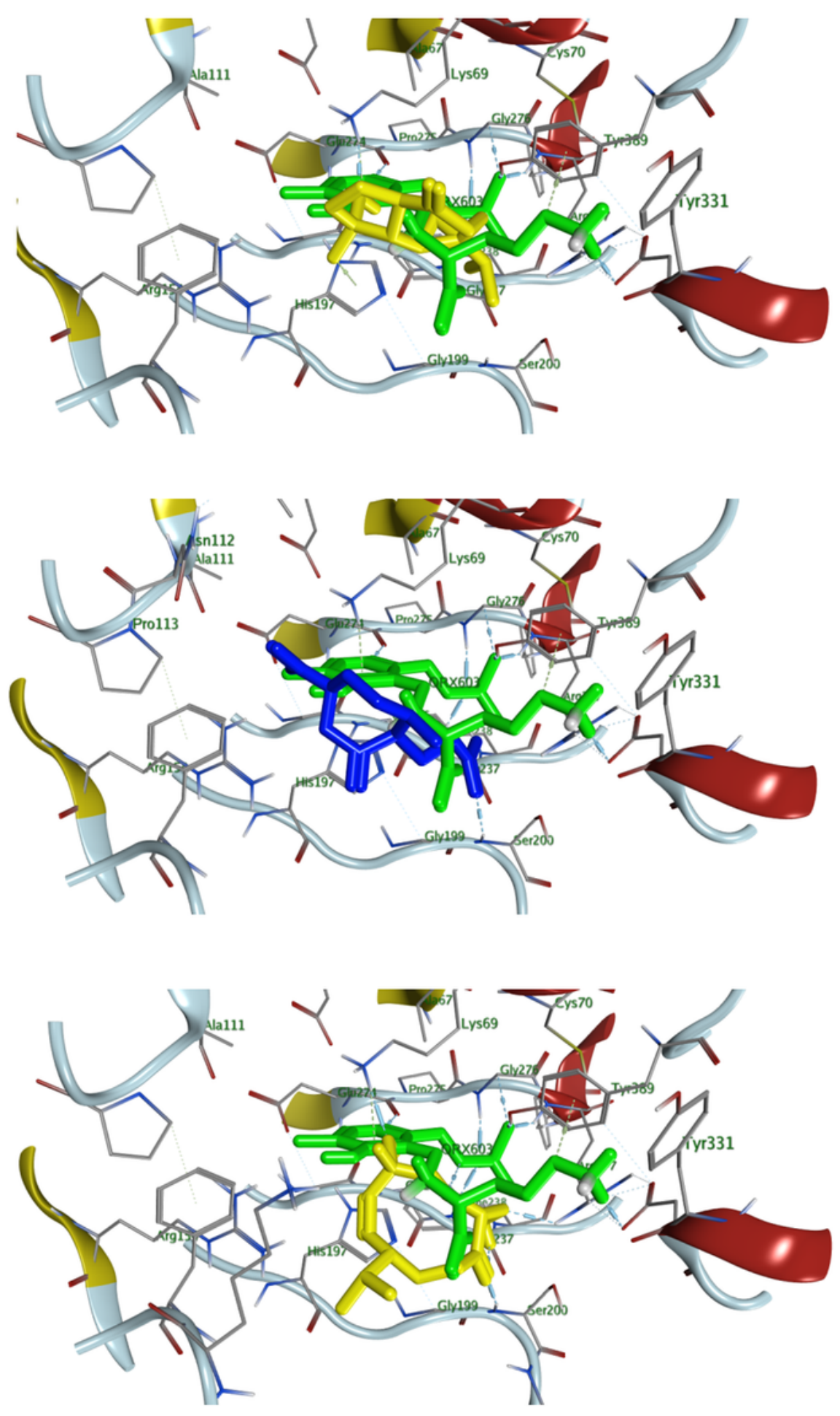

(a)

(b)

\section{Figure 4}

3D presentation of 6,7-epoxy-4-hydroxyguaian-10-ene (yellow-color; (a), chabrolidione A (blue-color; (b), nephtheoxydiol (yellow-color; (c) overlay within 1NJJ active site and its ligand (ORX; green-color) 


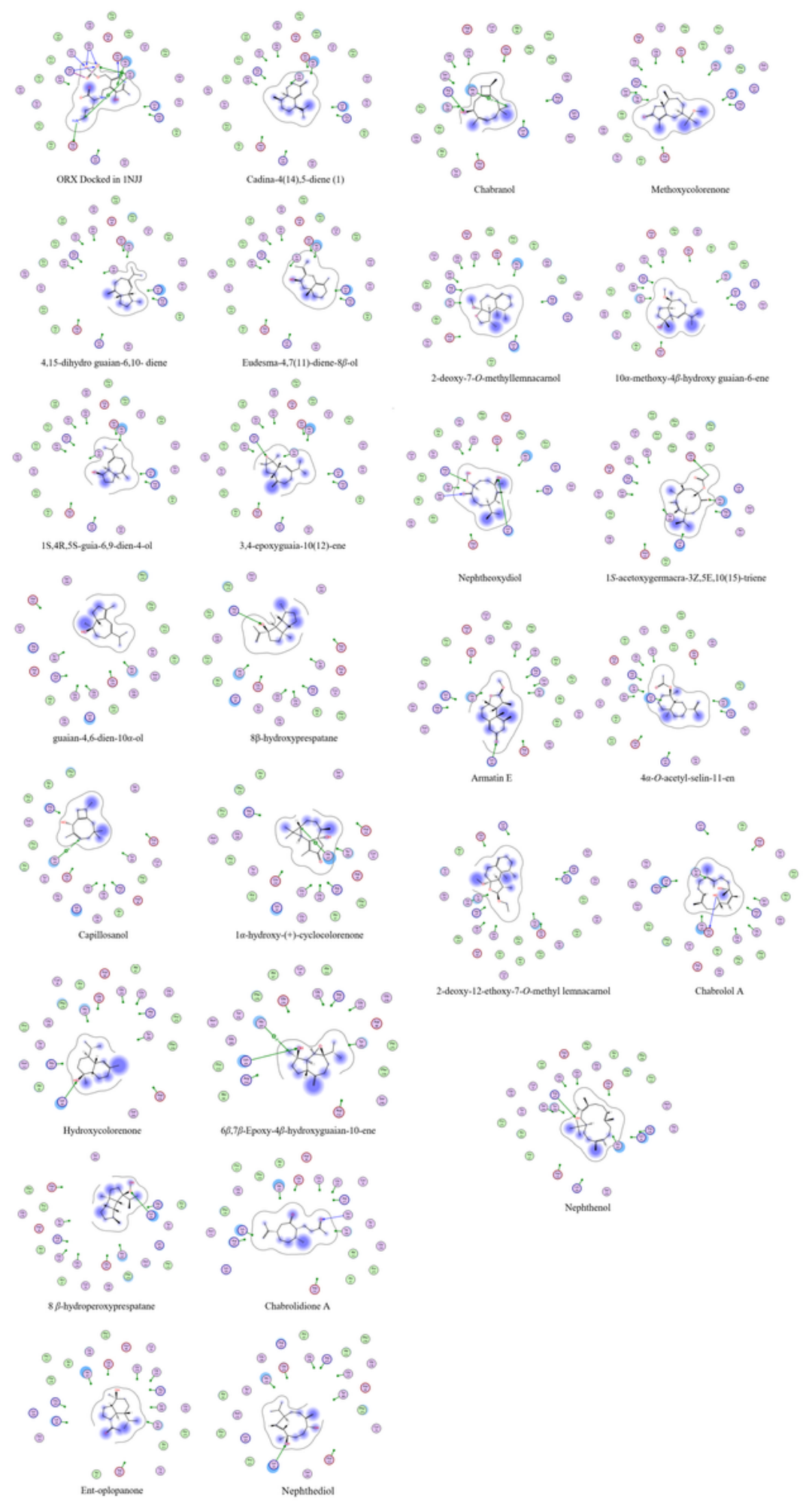

Figure 5

$2 \mathrm{D}$ interaction diagrams in the active site $1 \mathrm{NJJ}$ made by the co-crystallized ligand (ORX) and the dereplicated compounds. The MOE software generates the diagrams.

\section{Supplementary Files}


This is a list of supplementary files associated with this preprint. Click to download.

- Graphicalabstract.jpg 